\title{
Physiological and transcriptional responses and cross protection of Lactobacillus plantarum ZDY2013 under acid stress
}

\author{
Renhui Huang, ${ }^{*} \dagger$ Mingfang Pan, ${ }^{*} \dagger$ Cuixiang Wan, ${ }^{* 1}$ Nagendra P. Shah, $\ddagger$ Xueying Tao, ${ }^{*} \dagger$ and Hua Wei ${ }^{*} \dagger$ \\ *State Key Laboratory of Food Science and Technology, Nanchang University, Nanchang 330047, P. R. China \\ †Jiangxi-OAI Joint Research Institute, Nanchang University, 235 Nanjing Donglu, Nanchang 330047, P. R. China \\ fFood and Nutritional Science, School of Biological Science, The University of Hong Kong, Pokfulam Road, Hong Kong, China
}

\begin{abstract}
Acid tolerance responses (ATR) in Lactobacillus plantarum ZDY2013 were investigated at physiological and molecular levels. A comparison of composition of cell membrane fatty acids (CMFA) between acidchallenged and unchallenged cells showed that acid adaptation evoked a significantly higher percentage of saturated fatty acids and cyclopropane fatty acids in acid-challenged than in unchallenged cells. In addition, reverse transcription-quantitative PCR analysis in acid-adapted cells at different $\mathrm{pH}$ values (ranging from 3.0 to 4.0 ) indicated that several genes were differently regulated, including those related to proton pumps, amino acid metabolism, sugar metabolism, and class I and class III stress response pathways. Expression of genes involved in fatty acid synthesis and production of alkali was significantly upregulated. Upon exposure to $\mathrm{pH} 4.5$ for $2 \mathrm{~h}$, a higher survival rate (higher viable cell count) of Lactobacillus plantarum ZDY2013 was achieved following an additional challenge to 40 $\mathrm{m} M$ hydrogen peroxide for $60 \mathrm{~min}$, but no difference in survival rate of cells was found with further challenge to heat, ethanol, or salt. Therefore, we concluded that the physiological and metabolic changes of acid-treated cells of Lactobacillus plantarum ZDY2013 help the cells resist damage caused by acid, and further initiated global response signals to bring the whole cell into a state of defense to other stress factors, especially hydrogen peroxide.
\end{abstract}

Key words: acid tolerance response, Lactobacillus plantarum, physiological and transcriptional level, cross-protection

\section{INTRODUCTION}

Lactic acid bacteria (LAB) have traditionally been recognized as probiotics and are used in commercial

Received June 20, 2015.

Accepted August 27, 2015.

${ }^{1}$ Corresponding author: cuixiangwan@ncu.edu.cn products for their health-promoting and nutritional benefits. However, LAB encounter various stress conditions during industrial processes and in the gastrointestinal tract (Mills et al., 2011), including high temperature, ethanol (van Bokhorst-van de Veen et al., 2011), hydrochloric acid, organic acids (lactic acid and acetic acid) (Broadbent et al., 2010; Mols et al., 2010), bile salts (Koskenniemi et al., 2011; Alcántara and Zuniga, 2012), gastric juices, and digestive enzymes (Bove et al., 2013). Among these challenges, acid stress is an inevitable hurdle for the survival of LAB. Several studies have confirmed that administration of high populations of LAB or probiotics provide beneficial effects (Mills et al., 2011; Bove et al., 2013); hence, acid resistance of an organism is a vital physiological attribute for its survival in the gut. Therefore, analysis of the acid tolerance response (ATR) would be helpful for understanding the mechanisms of survival in low $\mathrm{pH}$ and other stressful environments.

The possible mechanisms of ATR include proton pumps, production of an alkaline substance, changes in cell membrane, and protection or repair of macromolecules (Cotter and Hill, 2003; Wu et al., 2013). Studies in Lactobacillus casei showed that the content of cytoplasmic membrane fatty acid (CMFA) was altered to increase the proportion of $\mathrm{C} 18: 1$ and cyclopropane fatty acid (C19:0) in response to acid challenge (Broadbent et al., 2010). The $\mathrm{H}^{+}$-ATPase pathway, glutamic acid decarboxylation, and production of alkaline substances (through the arginine deiminase system) are the main systems involved in $\mathrm{pH}$ homeostasis in LAB (Cotter and Hill, 2003). Genes and proteins involved in $\mathrm{pH}$ homeostasis and cell protection or repair play a key role in acid adaptation (Mols et al., 2010; Mols and Abee, 2011). O'Sullivan and Condon (1999) reported that a high level of $\mathrm{H}^{+}$-ATPase was associated with strong acid tolerance in Lactococcus lactis at sub-lethal levels of acid. Research on Lactococcus reuteri 100-23 showed that putative glutamate decarboxylase, which converts glutamate to $\gamma$-aminobutyric acid, contributed to its acid resistance (Su et al., 2011). Arginine deiminase and glutamate decarboxylase were reported to confer 
resistance of $L c$. reuteri 100-23 to lactate (Teixeira et al., 2014). Phosphofructokinase (Pfk) and pyruvate kinase (Pyk) provide cells with strong ability to control glycolytic flux, resulting in ATP production, thus providing more energy for cells to pump protons under acidic conditions (Koebmann et al., 2005; Viana et al., 2005; Wu et al., 2012a). However, information on the mechanisms for Lactobacillus plantarum to modulate ATR and CMFA content and the cross-protective effect on other stresses are not fully understood.

Lactobacillus plantarum ZDY2013, isolated and confirmed in our previous work, is one of the dominant strains in fermented acid bean from a village in the western part of Fujian Province in China. We have demonstrated that the organism exhibits high acid stress resistance (to $\mathrm{HCl}$ and gastric juice) and possesses antibacterial and gut microbiota modulation properties (Huang et al., 2015).

In this study, we analyzed physiological changes in the cells of $L b$. plantarum caused by exposure to a low $\mathrm{pH}$ environment and examined changes in the cell membrane lipid composition using GC-MS. Reverse transcription quantitative PCR (RT-qPCR) was used to determine the changes in transcription levels of genes involved in CMFA synthesis, cellular metabolism, energy production, and class I and class III stress response pathways. Furthermore, we examined the cross-protective effect of ATR on other environment stressors, including high temperature, ethanol, salt, and hydrogen peroxide.

\section{MATERIALS AND METHODS}

\section{Strain and Growth Conditions}

Lactobacillus plantarum ZDY2013 was isolated as previously reported (Huang et al., 2015). A single colony of Lb. plantarum ZDY2013 was inoculated in 5 $\mathrm{mL}$ of de Man, Rogosa, and Sharpe (MRS) broth at $\mathrm{pH} 6.5$, followed by an overnight incubation at $37^{\circ} \mathrm{C}$. Cells at log phase $\left(10^{7} \mathrm{cfu} / \mathrm{mL}\right)$ were transferred to a 0.5-L triangle bottle and grown overnight $(24 \mathrm{~h})$; early stationary phase cells were used to prepare cell suspensions. A typical Lactobacillus spp., Lactobacillus plantarum ATCC 8014, was used as a comparison.

\section{Measurement of Intracellular pH and ATP}

The cell suspension was adjusted the $\mathrm{pH}$ to $6.5,4.5$, and 3.0 using $\mathrm{HCl}(1 \mathrm{M})$, and incubated at $37^{\circ} \mathrm{C}$ for 1 h. Viable cells were enumerated after acid challenge. Intracellular $\mathrm{pH}$ (pHi) was measured by using the fluorescence method developed by Breeuwer et al. (1996), using 5 (and 6-)-carboxyfluorescein succinimidyl ester as the fluorescent probe. Loading of cells with 5 (and 6-)-carboxyfluorescein succinimidyl ester, determination of $\mathrm{pHi}$, and calibration of $\mathrm{pHi}$ all followed the procedures described previously (Breeuwer et al., 1996).

The ATP assay was carried out by using an ATP assay kit (Nanjing Jiancheng Bioengineering Institute, Nanjing, China) following the manufacturer's protocol. The final ATP concentration was expressed in nanomoles per milligram of protein. All ATP concentration values were the means of at least 3 independent extractions.

\section{Analysis of CMFA Composition Using GC-MS}

Lactobacillus plantarum ZDY2013 was grown in MRS broth for $24 \mathrm{~h}$ at $37^{\circ} \mathrm{C}$, and $1 \mathrm{M} \mathrm{HCl}$ was used to adjust the $\mathrm{pH}$ to 6 . Then, the cells were exposed to $\mathrm{pH} 3.5$ and incubated for $2 \mathrm{~h}$, followed by CMFA extraction from the cells. All solvents used in preparation of FAME were HPLC grade, and all glassware was washed with distilled water in an ultrasonic cleaner before use. The FAME of CMFA were prepared as described previously (Sasser, 1990; Wu et al., 2012b) with some modifications. Briefly, cells were collected by centrifugation $(5,500 \times g$ for $5 \mathrm{~min})$; then, cell pellets were washed with cold PBS buffer twice, and $1 \mathrm{~mL}$ of $\mathrm{NaOH}$ in a methanol-distilled water solution $(3: 10: 10 \mathrm{wt} / \mathrm{vol} / \mathrm{vol})$ was added. The suspension was heated at $100^{\circ} \mathrm{C}$ for $30 \mathrm{~min}$, and then cooled to room temperature $\left(24^{\circ} \mathrm{C}\right)$, and $2 \mathrm{~mL}$ of methanol:HCl:water $(22: 13: 13 \mathrm{vol} / \mathrm{vol} / \mathrm{vol})$ solution was added for methylation and the suspension heated at $80^{\circ} \mathrm{C}$ for $10 \mathrm{~min}$. After rapid cooling in an ice bath to $0^{\circ} \mathrm{C}$, FAME were extracted using $1.25 \mathrm{~mL}$ of methyl tert-butyl ether:hexane (1:1 vol/vol) for $10 \mathrm{~min}$ and washed with $3 \mathrm{~mL}$ of $0.33 \mathrm{M} \mathrm{NaOH}$. The upper layer was transferred into a 2 -mL vial using a Pasteur pipette, and evaporated to about $1 \mathrm{~mL}$ under a flow of nitrogen. For GC-MS analysis, $1 \mu \mathrm{L}$ of sample was injected into a gas chromatograph $(6890 \mathrm{~N}$, Agilent, Palo Alto, CA); the carrier gas was hydrogen $(1.0 \mathrm{~mL} / \mathrm{min})$. Running conditions were injector, $230^{\circ} \mathrm{C}$; ionization detector, $250^{\circ} \mathrm{C}$; and program temperature ramping from $120^{\circ} \mathrm{C}$ to $230^{\circ} \mathrm{C}$ at $6^{\circ} \mathrm{C} / \mathrm{min}$. The relative contents of FAME were determined by area normalization.

\section{RNA Extraction and cDNA Synthesis}

For transcriptional analysis, cells were centrifuged and pellets suspended in $10 \mathrm{~mL}$ of MRS, followed by adjustment of the $\mathrm{pH}$ to 6.5 (as unstressed control), 4.0, 3.5, and 3.0. Both unstressed and acid-stressed bacterial suspensions were incubated at $37^{\circ} \mathrm{C}$ for $30 \mathrm{~min}$ and then prepared for RNA extraction. 
Total RNA was extracted with Transzol reagent (TransGen Biotech, Beijing, China). Integrity and concentration of RNA were determined by agarose gel electrophoresis and spectrophotometer (NanoDrop 1000, Thermo Scientific, Waltham, MA). An aliquot (500 ng) of total RNA was used to synthesize cDNA by using a reverse transcription kit (Takara, Dalian, China) after genomic DNA was removed.

\section{Analysis of Gene Expression by $q P C R$}

To assess the transcriptional level of genes associated with the stress response, qPCR was performed on an ABI 7900HT fast real-time PCR system (Applied Biosystems, Waltham, MA). Two microliters of 10 -fold diluted cDNA was added to $15 \mu \mathrm{L}$ of a real-time PCR mix containing $10 \mu \mathrm{L}$ of SYBR Primer EX TaqII (Takara), $0.4 \mu \mathrm{L}$ of ROX reference dye (50×; Takara), 0.2 $\mu M$ of each primer (Supplementary Table S1; http:dx. doi.org/10.3168/jds.2015-9993), and $6 \mu \mathrm{L}$ of Milli-Q $\mathrm{H}_{2} \mathrm{O}$ (Millipore Corp., Billerica, MA). Thermal cycling started at $95^{\circ} \mathrm{C}$ for $1 \mathrm{~min}$ followed by 40 cycles at $95^{\circ} \mathrm{C}$ for $15 \mathrm{~s}, 60^{\circ} \mathrm{C}$ for $30 \mathrm{~s}$, and $72^{\circ} \mathrm{C}$ for $30 \mathrm{~s}$. The relative transcriptional level was analyzed through the $2^{-\Delta \Delta \mathrm{Ct}}$ (delta cycle threshold) method based on qPCR data according to Feng et al. (2010). Untreated bacterial cell suspension served as a calibrator condition, and expression of the lactate dehydrogenase $\mathrm{D}$ gene $(l d h D)$ was monitored to normalize the expression of target genes (Desroche et al., 2005; Fiocco et al., 2007; Bove et al., 2013). Melting curve analyses were performed to confirm the specificity of reaction.

\section{Cross-Protection Studies}

Gene expression responses, especially class I and class III stress regulation members, in $L b$. plantarum are differentially regulated in various different stress conditions, including ethanol, oxidative, solvent, and cold and heat stress according to van Bokhorst-van de Veen et al. (2013). To determine the cross-protection effect, the tolerance of untreated (unstressed) and $\mathrm{pH}$ 4.5 acid-stressed cells were compared under different environmental stress challenges. Lactobacillus plantarum ZDY2013 grown in MRS broth at $\mathrm{pH} 6.5$ was used as the control (unstressed condition). An aliquot $(5 \mathrm{~mL})$ was acid stressed for $2 \mathrm{~h}$ at $\mathrm{pH} 4.5$ and then washed in PBS before exposure to other stressors. For all stress tolerance assays, aliquots were serially diluted immediately after stress exposure, and then immediately plated on MRS agar and incubated at $37^{\circ} \mathrm{C}$ for 2 $\mathrm{d}$ before enumeration of colony-forming units.

To quantify survival of $L b$. plantarum ZDY2013 after oxidative stress, ZDY2013 cells before and after acid response were suspended in PBS with $40 \mathrm{~m} M$ hydrogen peroxide. Cells were collected every $10 \mathrm{~min}$ for enumeration. Cross-protection with ethanol stress was determined after the cells were suspended in PBS with $8 \%$ (vol/vol) ethanol. Subsequently, samples were collected at every $2 \mathrm{~h}$ in triplicate, followed by enumeration of viable cells. Similarly, for osmotic pressure and salt stress, cells were suspended in PBS with $3 \% \mathrm{NaCl}$. The heat resistance of ZDY2013 cells treated in pH 6.0 or 4.5 was assessed after suspending the cells in PBS and exposing them to $65^{\circ} \mathrm{C}$ for $30 \mathrm{~min}$ or $100^{\circ} \mathrm{C}$ for 10 $\min$.

\section{Statistical Analysis}

All results were expressed as means \pm standard deviations. Statistical analysis was performed using oneway ANOVA procedure of SPSS 13.0 software (SPSS Inc./IBM Corp., Chicago, IL). All experiments were performed in triplicate and all the analyses were carried out in duplicate.

\section{RESULTS}

\section{Intracellular $\mathrm{pH}$ and ATP}

The population decrease following acid challenge was related to the decrease in pHi. As shown in Figure 1A, Lb. plantarum ZDY2013 exhibited a higher survival rate during acid challenge than did $L b$. plantarum ATCC 8014. Furthermore, at pH 6.5, there was no obvious difference in $\mathrm{pHi}$ and ATP levels between Lb. plantarum ZDY2013 and Lb. plantarum ATCC 8014 (Figure 1B and 1C). However, a higher pHi and ATP level were detected in $L b$. plantarum ZDY2013 at both $\mathrm{pH} 4.5$ and 3.0 compared with that in Lb. plantarum ATCC 8014. Lactobacillus plantarum ZDY2013 (with high acid resistance) had a relatively higher pHi. The high ATP levels further suggested that $L b$. plantarum ZDY2013 might effectively prevent the rapid decline of pHi during acid challenge.

\section{Lipid Composition}

Cell membrane regulating substances entering or exiting cells play an important role in cellular growth, metabolism, energy transduction, and maintenance of a constant intracellular environment. The membrane fluidity of bacteria is decreased by changing the fatty acid composition to defend proton influx for the maintenance of $\mathrm{pH}$ homeostasis (Mykytczuk et al., 2007; Zhang and Rock, 2008). In this study, the main CMFA in Lb. plantarum ZDY2013, including C14:0, C16:0, C16:1, C18:0, C18:1, C18:2, and C19:0, made up over 
A

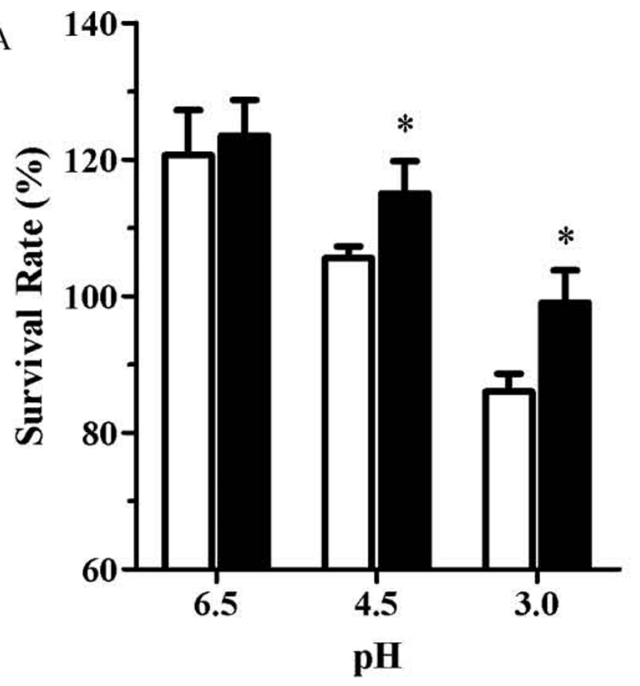

B
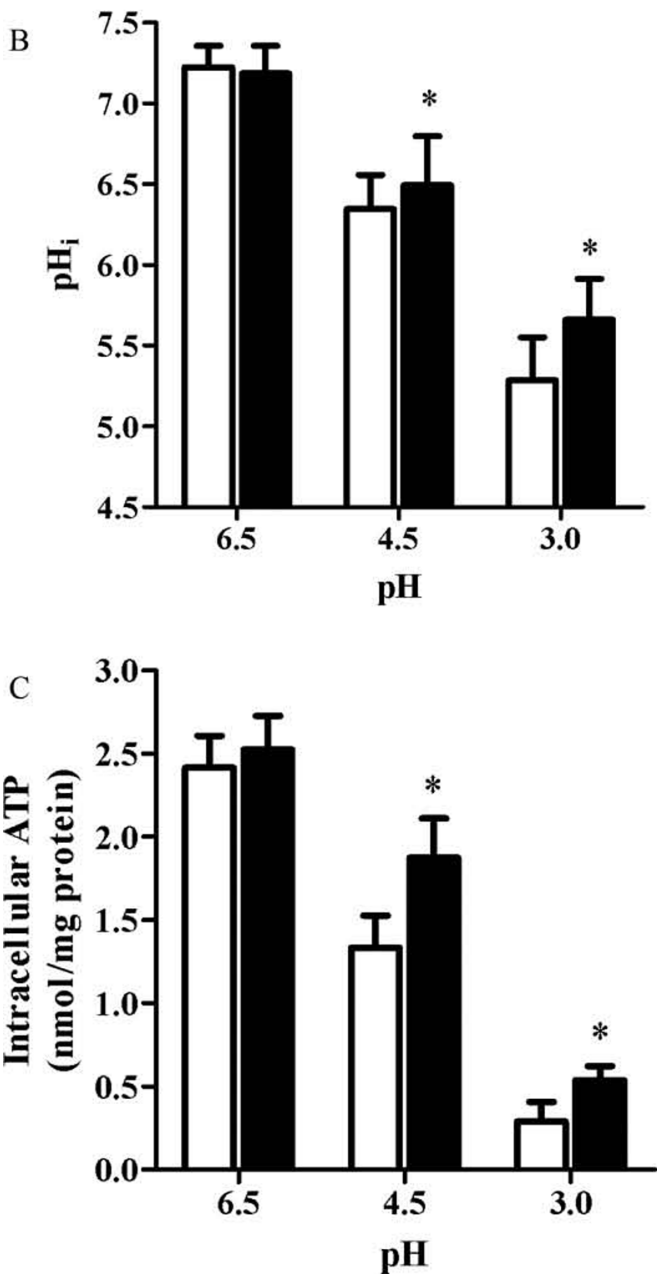

Figure 1. Changes in (A) survival rate, $(\mathrm{B})$ intracellular $\mathrm{pH}\left(\mathrm{pH}_{\mathrm{i}}\right)$, and (C) intracellular ATP concentration during acid stress. Cells resuspended at $\mathrm{pH} 6.5$ were exposed at $\mathrm{pH} 4.5$ or 3.0 for $1 \mathrm{~h}$. White bars represent Lactobacillus plantarum ATCC 8014, and black bars represent Lactobacillus plantarum ZDY2013. Error bars indicate standard deviations $(\mathrm{n}=3)$. Statistically significant differences $(P<0.05)$ were determined by Student's $t$-test and are indicated with an asterisk.
Table 1. Effect of acid challenge on the cell membrane fatty acid (CMFA) composition (\% of FA in total CMFA; mean \pm SD) of Lactobacillus plantarum ZDY2013

\begin{tabular}{|c|c|c|}
\hline \multirow[b]{2}{*}{ Fatty acid } & \multicolumn{2}{|c|}{ Treatment } \\
\hline & Control & Acid treated \\
\hline $\mathrm{C} 12: 0$ & $0.221 \pm 0.610$ & $0.381 \pm 0.089$ \\
\hline C14:0 & $3.228 \pm 0.467$ & $4.239 \pm 0.860$ \\
\hline C16:0 & $28.414 \pm 2.602$ & $34.285 \pm 1.509^{*}$ \\
\hline C18:0 & $1.298 \pm 0.219$ & $0.972 \pm 0.122$ \\
\hline C16:1 & $4.382 \pm 0.303$ & $3.437 \pm 0.203$ \\
\hline C18:1 & $29.872 \pm 1.933$ & $28.155 \pm 5.603$ \\
\hline $\mathrm{C} 18: 2$ & $22.518 \pm 7.565$ & $7.087 \pm 2.527^{*}$ \\
\hline C19:0(9c) & $10.068 \pm 2.430$ & $21.443 \pm 3.717^{*}$ \\
\hline SFA $(\%)$ & $30.160 \pm 2.629$ & $38.254 \pm 2.734$ \\
\hline Unsaturated FA (\%) & $69.840 \pm 2.629$ & $61.746 \pm 2.734$ \\
\hline SFA:unsaturated FA & $0.432 \pm 0.059$ & $0.663 \pm 0.012^{* *}$ \\
\hline
\end{tabular}

${ }^{*} P<0.05,{ }^{* *} P<0.01$, compared with unstressed condition.

96\% of the total CMFA content (Table 1). After acid treatment ( $\mathrm{pH} 3.0$ for $2 \mathrm{~h}$ ), the ratio of SFA to unsaturated FA in treated cells was as high as 0.66 , which was significantly higher than that for the control cells $(0.43$; $P<0.01$ ). The percentages of SFA (e.g., C14:0, C16:0) and cyclopropane (C19:0 cis-9) in acid-treated cells were higher than that of the control, whereas PUFA (C18:2) exhibited a significant decrease $(P<0.05)$. Lactobacillus plantarum ZDY2013 actively adjusted membrane fluidity by changing the lipid composition, indicating that the cell envelope was adapted to cope with the extreme acid condition.

\section{Transcriptional Analysis in Acid Response}

To further explore global changes in genes at the transcriptional level during acid stress, we carried out a comprehensive RT-qPCR analysis. A set of Lb. plantarum genes potentially involved in survival and stress tolerance was analyzed. The gene transcripts that were up- or downregulated belonged mainly to the following functional categories: (1) CMFA synthesis; (2) cellular metabolism and energy production, including amino acid and sugar metabolism, genes connected to proton pumps, and production of alkali; and (3) class I and class III stress response pathways, including transcriptional controller, posttranslational modification, protein turnover, and chaperones (van Bokhorst-van de Veen et al., 2011, 2013; Wu et al., 2012a; Bove et al., 2013).

\section{Membrane Lipid Synthesis}

We observed an obvious difference in gene expression of CMFA synthesis between pH 6.5 (control) and those at $\mathrm{pH} 4.0,3.5,3.0$ (Figure 2A). Transcription 
levels of acyl carrier proteins ( $a c p)$ and fatty acid/ phospholipid synthesis protein $(p l s X)$ were upregulated 3.46- and 1.56-fold, respectively, after acid treatment at $\mathrm{pH} 3.0$ for $2 \mathrm{~h}$. In addition, genes encoding fatty acid elongation proteins $(f a b F, f a b Z, f a b G)$ were activated at $\mathrm{pH} 3.0$ and were increased $6.13-, 5.83-$, and 5.02fold, respectively. Remarkably, cyclopropane fatty-acylphospholipid synthase ( $c f a 1$ ) was upregulated 1.54-fold, whereas its paralogue, $c f a 2$, was repressed. These results indicate that $L b$. plantarum ZDY2013 adapted its cell membrane structure by adjusting the transcription levels of genes involved in CMFA synthesis in response to acid stress.

\section{Cellular Metabolism and Energy Production}

Enzymes participating in glycolysis and ATP production may support an increase in $\mathrm{H}^{+}$expulsion under acid conditions. In this study, transcription levels of genes related to sugar catabolism, including phosphoglycerate kinase $(p g k)$, phosphocarrier protein $(p t s h), 6$-phosphofructokinase $(p f k)$, and pyruvate kinase $(p y k)$, were enhanced 1.08-, 1.92-, 2.24-, and 1.33-fold, respectively, during acid stress compared with that of the control (Figure 2B). These enzymes catalyze the conversion of fructose 6-phosphate and phosphoenolpyruvic acid into fructose 1,6-diphosphate and pyruvic acid, respectively. In addition, 3 genes $(a t p A$, atpD, and $g s p A)$ related to cellular metabolism and energy production were differentially expressed in acid-stressed and unstressed cells. In response to acid stress, genes involved in ATP synthase (atp $A$ and $a t p D)$ and glycerol-3-phosphate dehydrogenase $(g s p A)$ were upregulated 1.36-, 2.27-, and 2.04-fold, respectively, compared with those of unstressed cells (Figure 2C).

Conversion of aspartate into arginine can improve arginine catabolism and result in the production of ammonia, which can increase the intracellular $\mathrm{pH}$, concomitantly producing ATP. In this study, 4 genes involved in aspartate and arginine pathways were examined, including aspartate-ammonia ligase (asnA), argininosuccinate synthase $(\arg G)$, ornithine carbamoyltransferase $(\arg F)$, and arginine catabolic regulator $(\arg R)$. It is worth mentioning that gene $\operatorname{asn} A$, which catalyzes the conversion of aspartate into asparagine, was downregulated, whereas 3 other genes, $\arg G, \arg F$, and $\arg R$, which are involved in arginine synthesis and catabolism, were significantly upregulated. In particular, the transcription levels of $\arg G$ and $\arg F$ increased by 5.26 - and 17.90-fold, respectively, at $\mathrm{pH} 3.0$ (Figure 2D), compared with those of the unstressed cells. Consequently, the flux from aspartate to arginine increased but the flux to asparagine decreased. Another upregulated pathway in the acid-stressed cells was the conver- sion of glutamate into $\gamma$-aminobutyrate by glutamate decarboxylases.

Glutamate decarboxylases can combine a glutamate with an intracellular proton and exchange the glutamate for the more alkaline $\gamma$-aminobutyrate, which can neutralize the extracellular $\mathrm{pH}$ slightly. Furthermore, consumption of a proton resulted in an increase in the intracellular $\mathrm{pH}$. The glutamate decarboxylase gene $(\operatorname{gadB})$ was found to be upregulated 1.5-fold at $\mathrm{pH}$ 3.0 when cells were stressed for $30 \mathrm{~min}$ (Figure 2C). The glutamate dehydrogenase gene $(g d h)$, which can catalyze $\alpha$-ketoglutaric acid to form glutamate, also increased 2.3-fold. The increase in the glutamate synthesis flux could result in an increase in the substrate concentration of glutamate decarboxylases.

\section{Induction of Class I and Class III Stress Response Pathways}

Stress response transcriptional regulators HrcA and CtsR, which are associated with tolerance to one or more environmental stresses, as well as the genes under their control were differentially expressed under acid stress (Figure 2E). Transcriptions of $h r c A$ and 2 other genes that are predicted to be regulated or at least partially controlled by $h r c A$, dnaK, and groEL (encoding chaperones), were significantly upregulated after acid stress for $30 \mathrm{~min}$. Transcription of $c t s R$ was significantly repressed during acid stress, whereas genes predicted to be repressed by $c t s R$, including $c \operatorname{lp} B, \operatorname{clp} P$, and $\operatorname{clp} E$ (encoding proteases), were upregulated after acid stress. Other genes associated with tolerance to one or more environmental stresses were also differentially regulated after $30 \mathrm{~min}$ of acid stress, including proteolytic enzyme (ftsh, 2.0-fold), and heat response genes hsp1 and hsp3 (small heat shock protein, 1.8- and 3.6-fold, respectively; Figure 2E).

\section{Cross-Protective Effect of Acid-Induced Lb. plantarum ZDY2013 Cells}

Because class I and class III stress response pathways were activated in $L b$. plantarum ZDY2013 during growth in acid stress, we examined whether this strain could withstand other chemical or environmental stresses after exposure to acid stress. To examine the cross-protection of $L b$. plantarum ZDY2013, cultures kept at $\mathrm{pH} 4.5$ for $2 \mathrm{~h}$ were resuspended in PBS with 40 $\mathrm{m} M$ hydrogen peroxide or $8 \%$ ethanol, or were exposed to high temperatures $\left(63^{\circ} \mathrm{C}\right.$ and $\left.100^{\circ} \mathrm{C}\right)$, or to $5 \% \mathrm{NaCl}$. Among these stress conditions, only the resistance to hydrogen peroxide was enhanced significantly $(P<$ 0.05 ) and no difference was found in the survival of acid-stressed cells when exposed to other stressors. 
A

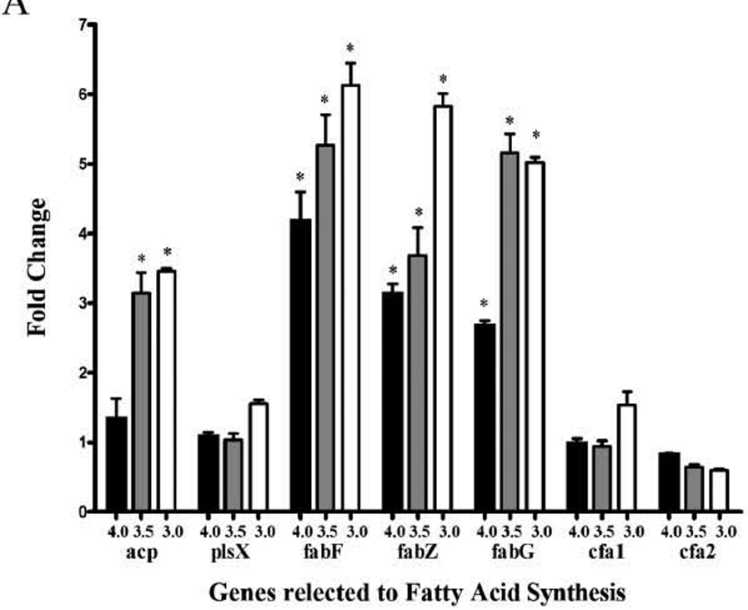

$\mathrm{C}$

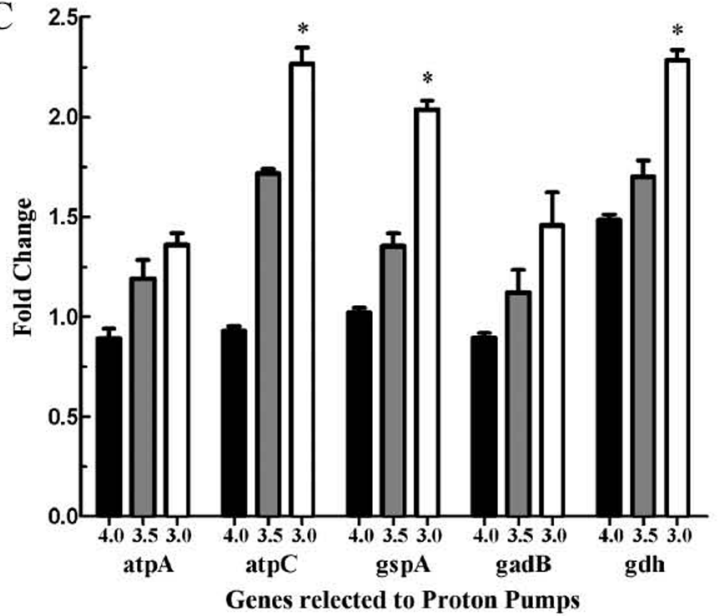

$\mathrm{E}$

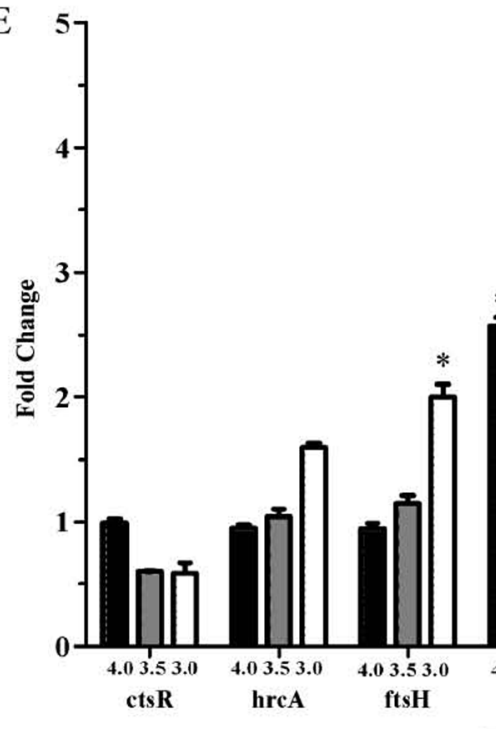

B

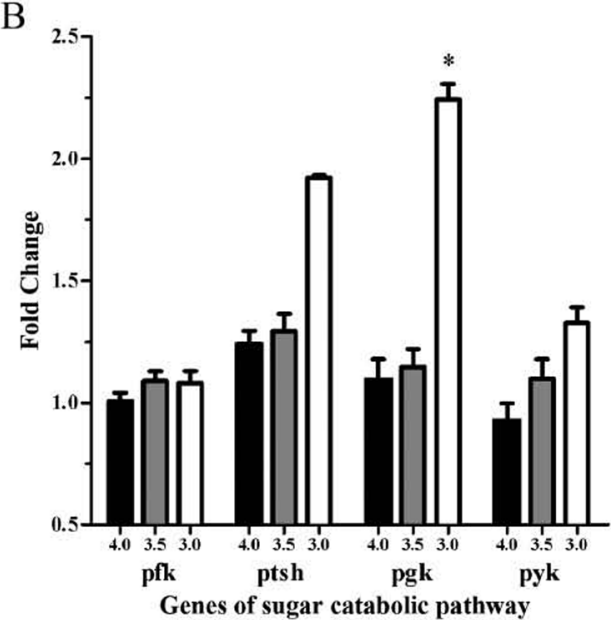

D

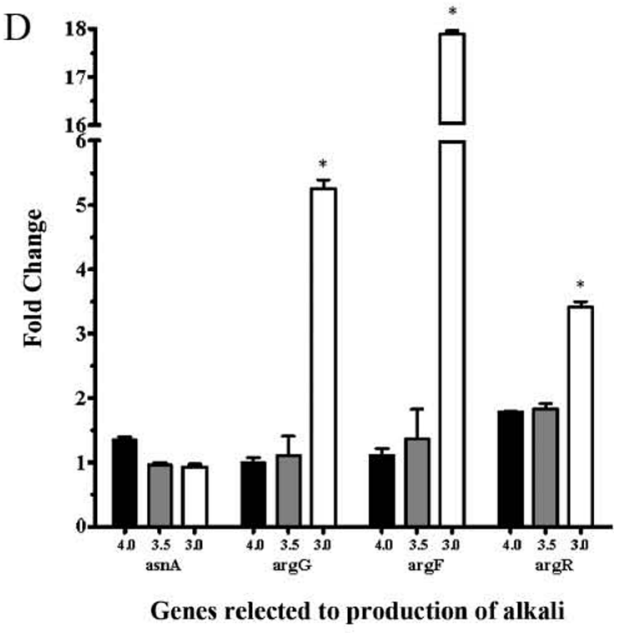
exhibited as fold changes of mRNA levels compared with control cells (unstressed, pH 6.5) and normalized using lactate dehydrogenase (ldhD) as internal control. Data are the means and standard deviations of 3 independent experiments. Genes related to (A) cell membrane fatty acid synthesis, (B) sugar catabolism, (C) proton pumps (including H-ATPase pathway and GAD pathway), (D) production of alkali (arginine deiminase pathway), and (E) class I and class III stress response pathways. Error bars indicate standard deviations (n = 3). Statistically significant differences $(P<0.05)$ are indicated with an asterisk. 


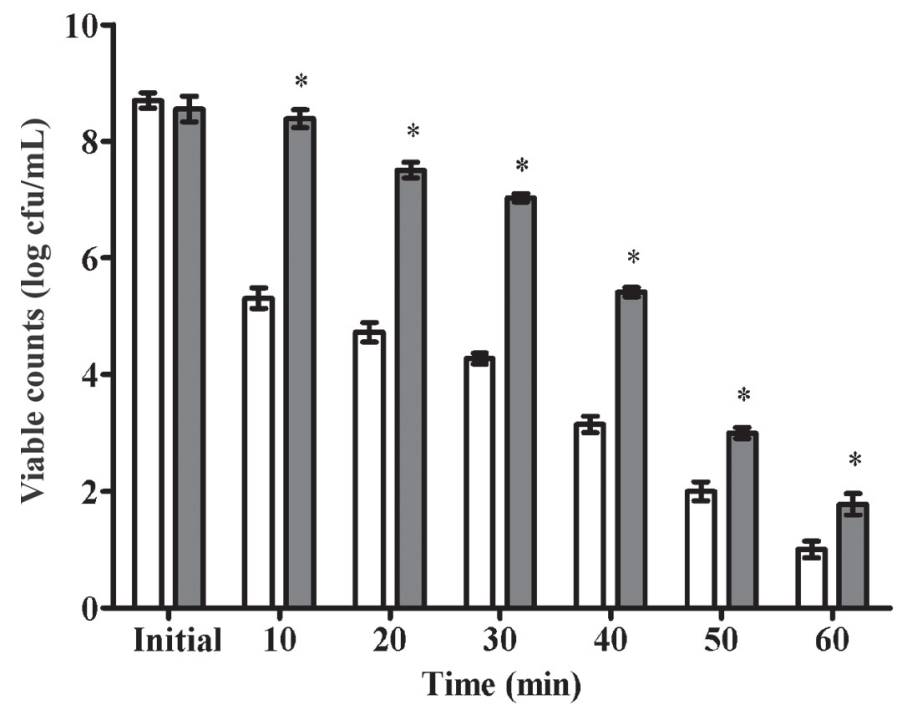

Figure 3. Cross protection against hydrogen peroxide of Lactobacillus plantarum ZDY2013 after adjusting the $\mathrm{pH}$ of de Man, Rogosa, and Sharpe broth to $\mathrm{pH} 4.5$ (gray bars) or control ( $\mathrm{pH} 6.5$, white bars) for $2 \mathrm{~h}$ and subjected to $40 \mathrm{~m} M$ hydrogen peroxide. Error bars indicate standard deviations $(\mathrm{n}=3)$. Statistically significant differences $(P<0.05)$ are indicated with an asterisk.

Lactobacillus plantarum ZDY2013 treated in MRS at $\mathrm{pH} 4.5$ for $2 \mathrm{~h}$ maintained greater survival in PBS containing $40 \mathrm{~m} M$ hydrogen peroxide during $60 \mathrm{~min}$ compared with the control (Figure 3). The viable cell counts of ZDY2013 in the control (pH 6.5) decreased rapidly when exposed to hydrogen peroxide at $40 \mathrm{~m} M$. However, cell counts of Lb. plantarum ZDY2013 at pH 4.5 were stable for the first 10 min when exposed to hydrogen peroxide, but subsequently decreased from 20 min and on.

\section{DISCUSSION}

Lactobacillus species, which are able to grow and survive under suboptimal conditions during food fermentation and gastrointestinal tract digestion, have attracted a lot of interest for their stress response mechanisms. In this study, we unraveled the adaptation strategy of $L b$. plantarum ZDY2013 that enables it to grow in medium at $\mathrm{pH} 3.5$ (Huang et al., 2015). This strain was shown to adapt by modulating basic metabolic pathways and cell membrane composition and by inducing stress response pathways. Transcriptional responses were elicited within $30 \mathrm{~min}$ of exposure to MRS medium at $\mathrm{pH} 4.0,3.5$, and 3.0. These adaptations resulted in cross-protection against hydrogen peroxide stress but not against other stressors.

A highly acidic environment results in the reduction of cytoplasmic $\mathrm{pH}\left(\mathrm{pH}_{\mathrm{i}}\right)$, which induces loss of activity of relevant acid-sensitive glycolytic enzymes and structural damage to macromolecules such as DNA and proteins (Cotter and Hill, 2003). As the first barrier between the external environment and the intracellular medium, the cell membrane is the primary defense against damage induced by environmental stress (Streit et al., 2008; Wu et al., 2012b). Moreover, bacteria decrease membrane fluidity by changing the fatty acid species and composition in defense of proton influx (Mykytczuk et al., 2007; Zhang and Rock, 2008). Analysis by GC-MS of the CMFA composition of $L b$. plantarum ZDY2013 demonstrated that the level of C18:2 in the cell membrane of L. plantarum ZDY2013 was reduced and the ratio of total SFA to unsaturated FA increased in acidtreated cells compared with unstressed cells. Changes in fatty acid levels were accompanied by changes in the expression of the corresponding genes; that is, synthesis of enzymes (as shown in Figure 2A). Therefore, the changes in lipid composition as monitored by GCMS and regulation of transcription of genes related to CMFA synthesis indicated that cell membrane regulation played an important role in the ATR process of $L b$. plantarum ZDY2013.

The core response to cope with the acid environment included intracellular ATP level. Bacteria modulate various basic metabolic pathways to enhance ATP production, which can help to pump protons out of cells (Broadbent et al., 2010). Previous studies reported that expression of phosphofructokinase $(p f k)$ and pyruvate kinase ( $p y k$; glycolytic enzymes that severely affect a cell's ability to produce ATP) provided cells the potential to control glycolytic flux (Koebmann et al., 2005; Viana et al., 2005). Similarly, in our study, acid-treated cells of ZDY2013 exhibited higher transcript levels of $p f k$ and $p g k$ than did the unstressed cells. Wu et al. (2012a) reported that the mutant of $L b$. casei Zhang with enhanced tolerance to lactic acid exhibited higher expression of $p f k$ and $p y k$ during acid stress. Therefore, the response of ZDY2013 enhanced sugar metabolism flux, which leads to an increase in ATP production to provide more energy to pump protons out of cells (Jin et al., 2012).

Transcriptional analyses of ZDY2013 verified that the genes atp $A$ and atp $C$, which encode $\mathrm{H}^{+}$-ATPase, were upregulated at $\mathrm{pH} 4.0$ or at lower $\mathrm{pH}$. Protontranslocating ATPase $\left(\mathrm{H}^{+}\right.$-ATPase) expels protons at the expense of consumption of ATP, which contributes to the expulsion of protons and consequently confers resistance to stress (McDonald et al., 1990; Hutkins and Nannen, 1993). Cytoplasmic $\mathrm{pH}$ (pHi) is reported to correlate with the cellular level of $\mathrm{H}^{+}$-ATPase (O'Sullivan and Condon, 1999).

Production of alkali was another core response of Lb. plantarum to acid stress. Transcriptional analyses 
suggest that $\arg G$ and $\arg F$, core genes involved in the arginine deiminase system, were dramatically upregulated under acid stress in the current study. The enhancement of flux from aspartate to arginine could lead to the production of ammonia and 1 mol of ATP per mol of arginine consumed (Wu et al., 2012a). Overall, ATP supplement system and $\mathrm{pH}$ neutralization play an important role in the physiological regulation of $L b$. plantarum ZDY2013 under acid stress.

Although we detected some overlap of gene transcriptional responses between one environment stress and another, adaptation of $L b$. plantarum to acid stress cross-protected this organism only against hydrogen peroxide. Similarly, van Bokhorst-van de Veen et al. (2011) noted that the induction of CtsR class III stress responses toward ethanol exposure provided cross protection to Lactobacillus plantarum WCFS1 against thermal stress but not against oxidative or high-salt stress. Generally, different cells initiated global response signals to bring the whole cell into a state of response to the stress, and thus exhibited resistance against other stressful environments; different cells presented different types of cross protection. For example, the induction of alkaline shock response enhances resistance of Enterococcus faecalis ATCC 19433 to bile salt (Flahaut et al., 1997).

Generally, there is some overlap of stress response for $L b$. plantarum to cope with different environments. van Bokhorst-van de Veen et al. (2013) reported that the CtsR and HrcA regulatory networks were invoked in different stress responses of $L b$. plantarum and illustrated that stress responses adapted with a complex nature. Similarly, a set of genes involved in tolerance to one or more environmental stresses was induced during the acid stress response in ZDY2013 (Figure 2E), including genes encoding regulatory proteins (driving genetic responses; i.e., cts $R$ and $f t s H$ ), chaperones (assisting in folding of misfolded proteins; i.e., dnaK and groEL), and proteases (degrading irreversibly damaged proteins; i.e., $\operatorname{clp} P$ ), which have been identified in various stress conditions (Wall et al., 2007; Seydlová et al., 2012; Bove et al., 2013; van Bokhorst-van de Veen et al., 2013). The groEL and $d n a K$ genes are class I heat shock genes controlled by the HrcA repressor (Schumann, 2003; Spano and Massa, 2006), whereas ftsH and $c l p$ genes belong to the CtsR regulon of $L b$. plantarum (Wall et al., 2007; Fiocco et al., 2009; Bove et al., 2012).

Supported by the physiological changes identified by GS-MS and transcriptional changes identified by RTqPCR, this study demonstrates that prior exposure to acid stress not only induces an ATR but also induces protection to stress from hydrogen peroxide.

\section{CONCLUSIONS}

In this study, Lb. plantarum ZDY2013 exhibited a complex adaptation strategy to deal with acid stress by changing fatty acid biosynthesis, regulating transcription level of genes associated with glycolysis and proton pumps, producing alkaline substances, and improving translational accuracy and protein folding, as well as modulating transcriptional regulation networks (class I and III stress response pathways). However, the physiological and molecular responses did not provide cross-protection against heat stress, ethanol, or bile salt stress, only against hydrogen peroxide stress.

\section{ACKNOWLEDGMENTS}

This project was sponsored by the National Natural Science Foundation of China (NSF31170091, 31360377, and 31260363), the Ganpo Talent Engineering 555 Project, the Academic and Technical Leaders Training Program for Major Subjects of Jiangxi Province (P. R. China), the Research Project of Jiangxi Provincial Education Department (GJJ13098; P. R. China), and the Postdoctoral Science Foundation Funded Project of China (M570567).

\section{REFERENCES}

Alcántara, C., and M. Zuniga. 2012. Proteomic and transcriptomic analysis of the response to bile stress of Lactobacillus casei BL23. Microbiology 158:1206-1218.

Bove, P., V. Capozzi, C. Garofalo, A. Rieu, G. Spano, and D. Fiocco. 2012. Inactivation of the ftsH gene of Lactobacillus plantarum WCFS1: Effects on growth, stress tolerance, cell surface properties and biofilm formation. Microbiol. Res. 167:187-193.

Bove, P., P. Russo, V. Capozzi, A. Gallone, G. Spano, and D. Fiocco. 2013. Lactobacillus plantarum passage through an oro-gastro-intestinal tract simulator: Carrier matrix effect and transcriptional analysis of genes associated to stress and probiosis. Microbiol. Res. 168:351-359

Breeuwer, P., J.-L. Drocourt, F. M. Rombouts, and T. Abee. 1996. A novel method for continuous determination of the intracellular $\mathrm{pH}$ in bacteria with the internally conjugated fluorescent probe 5 (and 6-)-carboxyfluorescein succinimidyl ester. Appl. Environ. Microbiol. 62:178-183.

Broadbent, J. R., R. L. Larsen, V. Deibel, and J. L. Steele. 2010 Physiological and transcriptional response of Lactobacillus casei ATCC 334 to acid stress. J. Bacteriol. 192:2445-2458.

Cotter, P. D., and C. Hill. 2003. Surviving the acid test: Responses of gram-positive bacteria to low pH. Microbiol. Mol. Biol. Rev. 67:429-453.

Desroche, N., C. Beltramo, and J. Guzzo. 2005. Determination of an internal control to apply reverse transcription quantitative PCR to study stress response in the lactic acid bacterium Oenococcus oeni. J. Microbiol. Methods 60:325-333.

Feng, Y., J. Gong, H. Yu, Y. Jin, J. Zhu, and Y. Han. 2010. Identification of changes in the composition of ileal bacterial microbiota of broiler chickens infected with Clostridium perfringens. Vet. Microbiol. 140:116-121.

Fiocco, D., M. Collins, L. Muscariello, P. Hols, M. Kleerebezem, T. Msadek, and G. Spano. 2009. The Lactobacillus plantarum $\mathrm{ftsH}$ 
gene is a novel member of the CtsR stress response regulon. J. Bacteriol. 191:1688-1694.

Fiocco, D., E. Crisetti, V. Capozzi, and G. Spano. 2007. Validation of an internal control gene to apply reverse transcription quantitative PCR to study heat, cold and ethanol stresses in Lactobacillus plantarum. World J. Microbiol. Biotechnol. 24:899-902.

Flahaut, S., A. Hartke, J.-C. Giaro, and Y. Auffray. 1997. Alkaline stress response in enterococcus faecalis: adaptation, cross-protection, and changes in protein synthesis. Appl. Environ. Microbiol. 63:812-814.

Huang, R., X. Tao, C. Wan, S. Li, H. Xu, F. Xu, N. P. Shah, and H. Wei. 2015. In vitro probiotic characteristics of Lactobacillus plantarum ZDY 2013 and its modulatory effect on gut microbiota of mice. J. Dairy Sci.98:5850-5861.

Hutkins, R. W., and N. L. Nannen. 1993. pH homeostasis in lactic acid bacteria. J. Dairy Sci. 76:2354-2365.

Jin, J., B. Zhang, H. Guo, J. Cui, L. Jiang, S. Song, M. Sun, and F. Ren. 2012. Mechanism analysis of acid tolerance response of $\mathrm{Bi}$ fidobacterium longum ssp. longum BBMN 68 by gene expression profile using RNA-sequencing. PLoS ONE 7:e50777.

Koebmann, B., C. Solem, and P. R. Jensen. 2005. Control analysis as a tool to understand the formation of the las operon in Lactococcus lactis. FEBS J. 272:2292-2303.

Koskenniemi, K., K. Laakso, J. Koponen, M. Kankainen, D. Greco, P. Auvinen, K. Savijoki, T. A. Nyman, A. Surakka, T. Salusjarvi, W. M. de Vos, S. Tynkkynen, N. Kalkkinen, and P. Varmanen. 2011. Proteomics and transcriptomics characterization of bile stress response in probiotic Lactobacillus rhamnosus GG. Mol. Cell Proteomics 10:M110002741.

McDonald, L. C., H. P. Fleming, and H. M. Hassan. 1990. Acid tolerance of Leuconostoc mesenteroides and Lactobacillus plantarum. Appl. Environ. Microbiol. 56:2120-2124.

Mills, S., C. Stanton, G. F. Fitzgerald, and R. P. Ross. 2011. Enhancing the stress responses of probiotics for a lifestyle from gut to product and back again. Microb. Cell Fact. 10(Suppl. 1):S19.

Mols, M., and T. Abee. 2011. Bacillus cereus responses to acid stress. Environ. Microbiol. 13:2835-2843.

Mols, M., R. van Kranenburg, M. H. Tempelaars, W. van Schaik, R. Moezelaar, and T. Abee. 2010. Comparative analysis of transcriptional and physiological responses of Bacillus cereus to organic and inorganic acid shocks. Int. J. Food Microbiol. 137:13-21.

Mykytczuk, N. C., J. T. Trevors, L. G. Leduc, and G. D. Ferroni. 2007. Fluorescence polarization in studies of bacterial cytoplasmic membrane fluidity under environmental stress. Prog. Biophys. Mol. Biol. 95:60-82.

O'Sullivan, E., and S. Condon. 1999. Relationship between acid Tolerance, cytoplasmic $\mathrm{pH}$, and ATP and $\mathrm{H}^{+}$-ATPase levels in chemostat cultures of Lactococcus lactis. Appl. Environ. Microbiol. 65:2287-2293.

Sasser, M. 1990. Technical note 101: Identification of bacteria by gas chromatography of cellular fatty acids. MIDI Inc., North Newark, DE.
Schumann, W. 2003. The Bacillus subtilis heat shock stimulon. Cell Stress Chaperones 8:207-217.

Seydlová, G., P. Halada, R. Fiser, O. Toman, A. Ulrych, and J. Svobodova. 2012. DnaK and GroEL chaperones are recruited to the $B a-$ cillus subtilis membrane after short-term ethanol stress. J. Appl. Microbiol. 112:765-774.

Spano, G., and S. Massa. 2006. Environmental stress response in wine lactic acid bacteria: Beyond Bacillus subtilis. Crit. Rev. Microbiol. 32:77-86.

Streit, F., J. Delettre, G. Corrieu, and C. Béal. 2008. Acid adaptation of Lactobacillus delbrueckii ssp. bulgaricus induces physiological responses at membrane and cytosolic levels that improves cryotolerance. J. Appl. Microbiol. 105:1071-1080.

Su, M. S., S. Schlicht, and M. G. Ganzle. 2011. Contribution of glutamate decarboxylase in Lactobacillus reuteri to acid resistance and persistence in sourdough fermentation. Microb. Cell Fact. 10(Suppl. 1):S8

Teixeira, J. S., A. Seeras, A. F. Sanchez-Maldonado, C. Zhang, M. S. Su, and M. G. Ganzle. 2014. Glutamine, glutamate, and arginine-based acid resistance in Lactobacillus reuteri. Food Microbiol. $42: 172-180$.

Van Bokhorst-van de Veen, H., T. Abee, M. Tempelaars, P. A. Bron, M. Kleerebezem, and M. L. Marco. 2011. Short- and long-term adaptation to ethanol stress and its cross-protective consequences in Lactobacillus plantarum. Appl. Environ. Microbiol. 77:5247-5256.

Van Bokhorst-van de Veen, H., R. S. Bongers, M. Wels, P. A. Bron and M. Kleerebezem. 2013. Transcriptome signatures of class I and III stress response deregulation in Lactobacillus plantarum reveal pleiotropic adaptation. Microb. Cell Fact. 12:112.

Viana, R., G. Perez-Martinez, J. Deutscher, and V. Monedero. 2005. The glycolytic genes $p f k$ and pyk from Lactobacillus casei are induced by sugars transported by the phosphoenolpyruvate:sugar phosphotransferase system and repressed by CcpA. Arch. Microbiol. 183:385-393.

Wall, T., K. Bath, R. A. Britton, H. Jonsson, J. Versalovic, and S. Roos. 2007. The early response to acid shock in Lactobacillus reuteri involves the $\mathrm{ClpL}$ chaperone and a putative cell wall-altering esterase. Appl. Environ. Microbiol. 73:3924-3935.

Wu, C., J. Zhang, W. Chen, M. Wang, G. Du, and J. Chen. 2012a. A combined physiological and proteomic approach to reveal lactic-acid-induced alterations in Lactobacillus casei Zhang and its mutant with enhanced lactic acid tolerance. Appl. Microbiol. Biotechnol. 93:707-722.

Wu, C., J. Zhang, G. Du, and J. Chen. 2013. Aspartate protects Lactobacillus casei against acid stress. Appl. Microbiol. Biotechnol. 97:4083-4093.

Wu, C., J. Zhang, M. Wang, G. Du, and J. Chen. 2012b. Lactobacillus casei combats acid stress by maintaining cell membrane functionality. J. Ind. Microbiol. Biotechnol. 39:1031-1039.

Zhang, Y. M., and C. O. Rock. 2008. Membrane lipid homeostasis in bacteria. Nat. Rev. Microbiol. 6:222-233. 